Discussion Paper No. 603

\title{
WHO SUPPORTS REDISTRIBUTION?
}

\author{
Fumio Ohtake \\ and \\ Jun Tomioka
}

May 2004

The Institute of Social and Economic Research Osaka University

6-1 Mihogaoka, Ibaraki, Osaka 567-0047, Japan 


\title{
Who Supports Redistribution?*
}

\author{
Fumio Ohtake \\ ISER, Osaka University, Osaka, Japan \\ ohtake@ iser.osaka-u.ac.jp \\ Jun Tomioka \\ Japan Center for Economic Research, Tokyo, Japan \\ tomioka@jcer.or.jp
}

\begin{abstract}
Using an original dataset, we investigated the determinants of individual preferences over income redistribution in Japan. Although income level is negatively correlated with support for redistribution, it does not explain much; there are other important factors, which relate to dynamics and uncertainty such as income risk. Even after controlling for income, both risk-averse individuals and those who expect to be unemployed in the future favor greater redistribution. Interaction of aging and mobility proved important. Relatively poor elderly, who presumably have few prospects of upward mobility, strongly support greater redistribution, whereas younger people are less sympathetic to such a policy.
\end{abstract}

Author Keywords: Income redistribution; Inequality; Uncertainty, Unemployment

JEL classification codes: D31; H23; I38

\footnotetext{
* This article is based on an Invited Lecture presented at the annual meeting of the Japanese Economic Association held at Meiji University, 12-13 October 2003. We are grateful to Yuji Genda, Takenori Inoki, Daiji Kawaguchi, an anonymous referee of this Journal, and seminar participants at the National Institute of Population and Social Security Research, Sophia University and the University of Tokyo for helpful comments. We appreciate financial supports from the Cabinet Office of the Japanese government, a Grant-in-Aid for Scientific Research from JSPS ( (B)(2)12124207 and (C)(2)14530109) and the 21st COE program.

${ }^{1}$ Studies on inequality, such as Tachibanaki (1998), Ishikawa (1999), and Sato (2000) among others, were published within a short period and attracted wide attention from researchers and the general public.
} 


\section{Introduction}

How do people perceive and evaluate economic inequality in society? In Japan, there has been a growing interest in income inequality among both the general public and academics. ${ }^{1}$

Representative indices of inequality, such as the Gini coefficient, have indeed exhibited a steady rise since around 1985. Economists have proposed several possible explanations for this trend, such as the aging of the population, technological development, the rise in unemployment, and changes in household structures (e.g., more double-income families and single-member households). On the other hand, throughout the 1990s, the extent of redistribution has declined, owing to the reduced progressiveness of income tax (Ohtake and Saito, 1999). Discussion of both positive and normative aspects of income differentials has not abated and continues to this day.

At the same time, it is striking how little is known about the way the general public assesses the existing distribution of economic resources and related policies. ${ }^{2}$ For example, one may conjecture that the poor favor income redistribution policies, as their net income normally benefits from these policies.

However, this view is too simple. Figure 1, which is based on our survey, shows how people's preferences for greater income redistribution vary with their household income. Although disapproval of redistribution clearly increases with income, there is a sizeable percentage of people in the highest income quartile who approve of such policies. In addition, respondents in the lower income groups do not necessarily support greater redistribution. ${ }^{3}$ The percentage of "not support" in the first income quartile is as large as $41.9 \%$ (which turns out to be identical with the percentage of "support" in the fourth income quartile).

It would be premature to conclude from this that people are not selfish, or lack the ability to compute personal payoffs. Benabou and Ok (2001) constructed a model in which currently poor

\footnotetext{
${ }^{2}$ For instance, we find it difficult to explain why a keen interest in income inequality has become apparent only in the late 1990s, which was almost ten years after the time (the late 1980s) when the index of inequality started showing an upward trend.

3 This also holds true when we use equivalent income scales instead, such as household income divided by the square root of the number of its members.
} 
individuals may oppose redistribution because they consider the potential loss from redistributive policies should they become rich in the future. Benabou and Ok refer to this as the Prospect of Upward Mobility (POUM) Hypothesis. Conversely, the rich may not necessarily oppose redistribution. Using a dataset from Russia, Ravallion and Lokshin (2000) have shown that even those who are currently rich tend to support redistribution if they expect their welfare to fall.

Using an original dataset, we attempt to reveal the determinants of individual preferences for income redistribution. We show that, although income is negatively correlated with support for redistribution, it does not explain very much; there are other important factors, which relate to dynamics and uncertainty such as income risk. For instance, even after controlling for income, risk-averse individuals and those who expect to be unemployed in the future show a strong tendency to support greater redistribution.

It was not until recently that economists began extensive use of people's subjective opinions in econometric analysis. Among current studies is one of people's preferences over income distribution and policy.

Redistributive policies normally entail a conflict of interests. Understanding the determinants of individual preferences over redistribution may provide interesting (and yet unexplored) policy implications. Furthermore, in a democratic state, the size of government as well as specific government policies must be determined in accordance with the preferences of its members. We expect our research to shed light on fundamental issues such as the origins of the welfare state and the minimal state, and why some countries have more equal income distribution than others. ${ }^{4}$

We did not rely on an existing survey. Rather, we designed and conducted an original survey, which enabled us to analyze preferences over redistribution in several new ways. For instance, we have information on individual characteristics that are important from an economic point of view,

\footnotetext{
${ }^{4}$ Classical economists, such as Ricard and Marx, believed that inequality could not persist in democracies. Yet this has not turned out to be the case, and the reasons are by no means obvious. " [I]f equalization of the distribution of wealth is possible through the electoral process, and if it is in the interest of the large majority of people (as would appear to be the case since median wealth is far below mean wealth in all capitalist democracies), why is it not implemented through political action by rational citizens?" (Putterman et al., 1998)
} 
including attitudes toward risk, time preference, subjective and objective social mobilities, many of which have not previously been available. Further, we asked detailed questions about income distribution from both positive and normative perspectives. We describe our dataset and variables in detail later.

The remainder of the paper is organized as follows. In Section 2, we discuss the determinants of preferences over redistribution. In Section 3, we present the estimable model and explain our dataset. In Section 4, we report the estimation results. Section 5 concludes.

\section{The Determinants of Preferences Over Redistribution}

We list below a set of possible determinants of preferences over redistribution that will be tested in our empirical analysis.

\section{(1) Current income}

Under the standard assumption of self-interested economic agents in a static and deterministic environment, the poor should favor redistribution while the rich oppose it. Meltzer and Richards (1981) consider an economy that consists of individuals with varying productivity, upon which a linear income tax is levied, the rate of which is determined by majority voting. The government redistributes the revenue in a lump-sum manner. The voter with the median income is decisive, in that the tax rate he or she prefers is the one that is socially chosen. Voters with income below (resp. above) the income of the decisive voter demand more (resp. less) redistribution than does the median voter. The extent of redistribution (the tax rate) is increasing in the ratio of the mean income to the median income, so a society that has a larger percentage of poor people will have a more extensive redistribution. This static median-voter model is the benchmark for our study. ${ }^{5}$ Its prediction will be modified once we introduce dynamics and uncertainty into the picture, as

\footnotetext{
${ }^{5}$ Strictly, the model we estimate is not the median voter model per se. Our dependent variable is an indicator of whether the respondent agrees to greater redistribution. This is probably a better way to test the essential idea of the median voter claim on redistribution. A direct test of the median voter model using electoral data in this context would face a difficulty from the outset, for, in reality, electoral politics concerns not only redistributive tax but several different
} 
discussed below.

(2) Expected income and social mobility

In a dynamic setting, coupled with upward social mobility and persistent redistributive policies over a certain time period, agents' expectations about future income will also matter: today's poor who are confident of becoming rich in the future will be net losers from redistribution in the long run, so they may not agree to redistribution today. On the other hand, those who are currently well off may be less so in future, and to the extent that they perceive this, may well demand redistribution now. Benabou and Ok (2001) formalize this idea, which they call the Prospect of Upward Mobility (POUM) Hypothesis. Alesina and La Ferrara (2001) constructed an index of income mobility using the Panel Study of Income Dynamics and tested the POUM hypothesis. They found a negative correlation between regional mobility and individual support for redistribution. Using a dataset from Russia, Ravallion and Lokshin (2000) showed that even those who are currently rich tend to support redistribution if they are expecting a decline in their welfare.

(3) Income inequality

If individual utility functions are such that people care about their relative position in society rather than their absolute level of personal income or consumption, greater inequality can make the poor (comparing themselves with the rich) unhappy, and the rich (comparing themselves with the poor) happy, and people will favor income redistribution policies accordingly. ${ }^{6}$ Some people may simply dislike inequality because it offends their sense of equity. Alesina, Di Tella and MacCulloch (2001) show that a person's subjective well-being can be negatively affected by

issues (e.g., religion and racial policy) simultaneously. The multidimensionality of issues is a plausible reason why the prediction of the standard median voter model has failed in actuality (see Putterman et al., 1998).

${ }^{6}$ Boskin and Sheshinski (1978) studied the optimal income tax when individuals are concerned with relative as well as absolute income, and showed that the optimal tax rate could be much higher than those derived under the standard assumption that only absolute income matters. 
greater income inequality if he or she holds leftist ideas. Another possibility is that people perceive greater inequality as a rise in income risk, and require more redistribution to prepare for this increased uncertainty.

(4) Faith in equality of opportunities

People may not approve of inequality if they feel that 'equal opportunity for all' is not guaranteed in society. Alesina and La Ferrara (2001) found that equality of opportunity is a necessary condition for Americans to see greater social mobility as a substitute to redistribution.

(5) Past income, consumption and previous experience

Individuals probably have an imperfect knowledge about the objective probability of upward or downward social mobility. Their own experiences may then serve as crucial information when they form perceptions about mobility. One's personal history concerning income, employment, and educational background (one's parents' as well) can have an important influence on whether one is optimistic or pessimistic about one's future, as well as how much faith one has in the equality of opportunity in the society. Piketty (1995) formalizes this type of idea in a Bayesian learning model. Empirical investigation by Alesina and La Ferrara (2001), and Ravallion and Lokshin (2000) confirmed this conjecture by finding past personal experiences important for the formation of opinions about income redistribution.

\section{(6) Risk aversion}

If an individual is uncertain about future income, risk aversion implies that he or she will be ready to give up some money to obtain a guaranteed income. The amount given up will be greater for those who are more risk averse, for whom income redistribution may be desirable as a social insurance against uncertainty, even though the current net benefit from such a policy is negative. Empirical studies have used a self-employment dummy as an inverse proxy for risk aversion. 
Alesina and La Ferrara (2001) found that the self-employed do indeed oppose redistribution. The validity of this proxy has not been tested and is debatable. Our original survey enabled us to create two different, direct indices of risk aversion: one is the standard certainty equivalent, derived from a question on financial commodities. The other is obtained from the lowest percentage of rainfall in a weather forecast that makes the respondent take an umbrella with him or her when going out.

(7) Age

As one approaches retirement age, the prospect of moving up the income ladder is likely to decrease. At least, one has a shorter time left to do so. One would then perceive the degree of substitution between social mobility and income redistribution to be weaker, and one would come to favor redistribution. Such a positive correlation between age and support for more redistribution, if any, should be evident among lower-income earners, for it is they who currently benefit most from such a policy. At one extreme are the relatively poor, retired elderly who have no prospect of entering the labor market again (and therefore no possibility of experiencing upward mobility). Our hypothesis implies that the effects of age on support for greater redistribution should be positive and larger among these people than those for any other age and income group. An analysis of how age relates to preferences for redistribution is also of interest considering that Japan is an unusually rapidly aging society.

(8) Prospect of unemployment

Even after controlling for income and consumption, the anticipation of unemployment can influence one's welfare and preference over income redistribution. Indeed, recent econometric analysis of subjective well-being showed that unemployment involves not only monetary loss but also various psychological shocks to the unemployed, such as the loss of self-confidence and of feelings of attachment to the workplace (Frey and Stutzer, 2002a, Ohtake and Tomioka, 2004). 
Nonfinancial costs of expected unemployment could therefore be a significant source of demand for social safety nets, including a greater redistribution policy.

\section{(9) Altruism}

This factor could be important in either a static or a dynamic environment. Even wealthy individuals may agree to redistribution solely on the basis of altruism if they see redistribution as a substitute for charity. Alesina, Glaeser and Sacerdote (2001) suggest that while Europeans have greater public provision of welfare than Americans, the US has more private provision of welfare (voluntary donations) to the poor than do European countries, and one cannot attribute this to the differences in taxation systems.

(10) Externalities and public goods

Redistribution need not involve a conflict of interests, or a trade-off between equity and efficiency. It can be efficiency enhancing. Redistribution can compensate for capital-market imperfections (due to, say, high transaction costs or asymmetric information), and thus may have beneficial effects on economic efficiency (Barr, 1992, Boadway and Keen, 2000, Krueger, 2002). The rich may well understand public-good aspects of various policies, such as the need for state intervention in the provision of infrastructure and education in a well-functioning society. These policies have a redistributive consequence under a nonregressive taxation system. Greater poverty can give rise to social unrest or increased crime, from which the rich will have a greater fear of being injured parties. For these reasons the wealthy may, acting on their own self-interest, rationally vote for extensive redistribution. In addition, government intervention to offset these adverse externalities would be desirable as an efficient solution to the free-rider problem (social prisoner's dilemma) that would prevail when redistribution is to be done through voluntary donations by the rich. 


\section{Econometric Model and Data}

\subsection{Model and estimation strategy}

We assume that the preferences of individual $i$ over redistribution policy can be described using the following latent variable model:

$$
Y_{i}^{*}=X_{i} \beta+U_{i} \gamma+M_{i} \lambda+\varepsilon_{i}
$$

where $Y_{i}^{*}$ is unobserved and takes a higher value the more individual $i$ favors greater redistribution. $X_{i}$ is a vector of individual characteristics such as gender, age, educational background, income, the degree of risk aversion, and the degree of altruism. $U_{i}$ is a dummy that equals unity if the respondent experienced unemployment in the past five years. If the estimated coefficient of this variable is positive and large, one can conclude that those who have been unemployed in the recent past will vote for redistribution by the state. $M_{i}$ is a binary variable that is unity when the respondent thinks that upward social mobility has recently increased. If $\lambda$ is negative, the interpretation is that social mobility and redistribution policy are substitutes. $\varepsilon_{i}$ is an error term.

In practice, we do not observe $Y_{i}^{*}$. We define a binary variable $Y_{i}$, which is unity if the respondent shows support for more redistribution, and zero otherwise. ${ }^{7}$ It also satisfies the following condition:

$$
\begin{aligned}
& Y_{i}=0 \text { if } Y_{i}^{*}<0 \\
& Y_{i}=1 \text { if } 0 \leq Y_{i}^{*}
\end{aligned}
$$

\footnotetext{
${ }^{7}$ Both Ravallion and Lokshin (2000) and Alesina and La Ferarra (2001) use survey questions that ask whether the respondent supports income redistribution in general. This may be too general a question and leave ambiguity. We believe it is useful to be somewhat more specific and ask, as we did in our survey, whether the respondent prefers more
} 
Assuming that $\varepsilon_{i}$ has a standard normal distribution and is independent of all the explanatory variables, probit estimation yields consistent estimates of the parameters. For statistical inference, we use cluster-robust standard errors to deal with the possible correlation of error terms within each cluster (due to some region-specific factor), while assuming no correlation across clusters. The appendix details variable definitions.

\subsection{Data and descriptive statistics}

Before presenting the results of the multivariate analysis, we describe our data and report some descriptive statistics. We designed a survey entitled "Survey on life and society". The survey was administered between 13 and 26 February, 2002. The population comprised adults aged between 20 and 65 in Japan. We sent the questionnaire to 6,000 persons selected at random. The number of respondents was 1,928 , which corresponds to a response rate of $32.1 \%{ }^{8}$ Survey questions included those on the Japanese economy (such as the causes of rising unemployment, determinants of individual income levels, changes in income distribution, preferences over various government policies), the current status of the respondent (income, wealth, expected income, experience of unemployment, happiness, class consciousness), and other individual characteristics (gender, age, educational background, occupation).

Our dependent variable is obtained from a question that asks whether the respondent supports or opposes "strengthening the redistribution of income from rich to poor using tax and other instruments of the social security system". The respondent could choose from a 1 to 5 scale for "Support" to "Oppose", with higher values indicating more support. From this, we created a binary variable that takes the value unity if the answer is favorable to redistribution and zero otherwise. We labeled this variable Redistr, and applied probit estimation.

or less redistribution than the current level, for in this way we know that the respondents share a common reference point. It also tells us whether they approve of the current extent of redistribution by the government.

8 The response rate is rather high for a mail-based sampling procedure. Moreover, the authors have found relatively small biases in the distributions of age, gender and income in our dataset, compared with the census and a representative survey such as the Japanese General Social Survey. Nevertheless, the possibility that our respondents are nonrandom in some other characteristics remains. 
In Tables 1 to 5, we present some descriptive statistics. Table 1 shows that approval of more redistribution is stronger in higher income groups. This is intuitively reasonable. However, it is also true that a significant proportion (about 40\%) of people in the lowest income quartile do not agree to greater redistribution, and around $40 \%$ of people in the highest income quartile do. In this sense, the current net benefit from income redistribution explains little of people's preferences over redistribution. In other words, a static median voter model with self-interested agents needs to be modified in some way.

In Table 2, we report preferences for redistribution according to age groups. The aged are more supportive of such policies, although there appears to be a nonlinear relationship. Table 3 shows that men tend to support redistribution more than do women. Interestingly, this is in sharp contrast to the evidence from other developed countries. Table 4 indicates that the unemployed are very likely to support more redistribution. Table 5 contains basic descriptive statistics of all the variables used in our multivariate analysis. Many respondents are quite conscious of the recent changes in income distribution. For instance, the average value of a binary variable IncomeIneq is about 0.66 , indicating that $66 \%$ of respondents think that income inequality has increased in the past five years. Similarly, the value of a dummy variable IncomeIneqFut implies that more than $75 \%$ of respondents expected income inequality to increase in the coming five years.

\section{Estimation Results}

\subsection{Basic model}

We begin with estimation of the effects of basic individual characteristics. Table 6 shows the estimated marginal effect of each explanatory variable on the dependent variable, and their cluster-adjusted standard errors.

In the first three rows, we look at the attitude across marital status and gender. The base group is married men. Females, especially married ones, turn out to favor redistribution less than do males. This contrasts with the findings in other developed countries. 
Next, we examine the effects of age. If, probably after a certain point, aging makes upward income mobility less likely (the elderly, at least, have a shorter time period to achieve a given degree of social mobility than young people do), then under the POUM hypothesis discussed above, older people should be more supportive of redistribution than are younger people. Furthermore, this finding should apply to low-income groups because they enjoy a net current income gain from redistribution.

The estimation results for the age dummies suggest that our conjecture is basically correct. The omitted category is for those in their twenties. Elderly people tend to be more favorable to greater redistribution, and this effect is very robust. Later we confirm that this result holds, as expected, only among lower-income groups.

Neither higher education (the omitted category is "less than college") nor real estate has any significant effect. On the other hand, those with larger household financial assets are less likely to accept redistribution. Similarly, higher household income is negatively correlated with support for redistribution (the base group is the first thirty percentile in terms of household income). These results on age, income and wealth suggest self-interested agents and are mostly consistent with what previous studies found in other developed countries.

Two points are worth noting in passing. First, our finding that women oppose redistribution contrasts with that of Alesina and La Ferrara (2001) for the US, and that of Ravallion and Lokshin (2000) for Russia. Alesina and La Ferrara argue that women (along with blacks) tend to support more redistribution, possibly because they perceive a lack of equal opportunities for all in America. Edlund and Pande (2002) provide evidence that as a result of the recent rise in the divorce rate, more American women are facing a decline in welfare, which makes them support the Democratic Party. We have seen that women in Japan, married or not, actually appear to disapprove of greater redistribution. ${ }^{9}$

\footnotetext{
9 The same results hold for women with and without jobs; they are less likely to agree to greater redistribution than are men. Also, the estimated coefficient for female remains virtually identical whether we control for risk aversion (discussed in detail below) or not, so the significance of gender in our estimate represents something other than the
} 
Secondly, previous studies also report the estimated impact of age on preferences. Ravallion and Lokshin (2000) show that, in Russia, the respondent's age is positively correlated with support for redistribution, which is similar to our result. On the other hand, Alesina and La Ferrara (2001) found that age has a negative and significant coefficient. The difference is interesting but we have not been able to explain it.

\subsection{Risk aversion}

Various government policies with a redistributive consequence have a public-insurance aspect. People who are relatively risk-averse may therefore rationally demand more redistribution, even if they are currently affluent enough to incur a net loss from such policies. To test this hypothesis, we created a rather novel proxy for risk aversion using the answer to the following survey question: "What is the lowest percentage of rainfall forecast that usually makes you bring an umbrella with you?" To be specific, we defined an index of risk aversion, RiskAvs, as 1 - (the respondent's answer)/100.

This index may vary widely across income groups, age groups, or by gender, but in a multiple regression, we can control for these factors. The overwhelming advantage of this index is that the original survey question is easy for respondents to understand and answer; it requires no special probability calculation. This is important, for most people are probably unfamiliar with calculating expected payoffs. On the other hand, most Japanese see weather forecasts in TV programs or newspapers everyday. In terms of simplicity, this is arguably the best available proxy for attitude towards risk.

Table 6 shows that this index has a positive and statistically significant coefficient (at the $1 \%$ level). A $10 \%$ increase in risk aversion implies a $2 \%$ increase in the probability that the respondent considers more redistribution to be desirable.

In our survey, we have a question from which another index of risk aversion (certainty

difference in attitudes toward risk. 
equivalent) could be constructed. The original survey question goes as follows. You are thinking of choosing a pension scheme from two alternatives. One scheme ensures a constant monthly flow of benefits, while the other provides either 300,000Yen or 100,000Yen per month with an even chance. We then asked the respondent to report the smallest amount of sure monthly income in the first pension plan that would make him/her indifferent between the two plans. We treat the suggested amount as an index of risk aversion, which broadly accords with the textbook definition of certainty equivalent. After analyzing the data, however, we concluded that this variable is not a very useful index. Probably, the question was unfamiliar and not well understood by many respondents. For instance, in a linear probability model we performed instrumental variable estimations in which we use this certainty equivalent as an IV for another index that we constructed, RiskAvs, assuming the classical error variance setup (for this kind of multiple indicator solution to the measurement error problem, see e.g., Wooldridge, 2002, Ch. 5.). We found that the coefficient of RiskAvs becomes statistically and economically insignificant. Conversely, when we instrumented the certainty equivalent measure by RiskAvs, we found the former's coefficient to be insignificant. Considering that RiskAvs is robustly estimated to be significant in the usual OLS and probit estimations, the above results suggest that our certainty equivalent measure is not a good indicator of true risk aversion. Another possible and deeper reason why this index does not work is that the simple expected utility framework is inappropriate in this context.

Empirical researchers (e.g., Alesina and La Ferrara, 2001) often use a self-employment dummy as an inverse proxy for risk-aversion. Alesina and La Ferrara showed that the self-employed tend to oppose redistribution. We also examined the effect of self-employment. The estimated coefficient on our self-employment dummy is indeed negative but also small and not statistically significant. However, we found subsequently that the relatively rich self-employed respondents are rather negative about increasing income redistribution, and that this is true even after controlling for income and our index of risk aversion. Therefore, 
self-employment probably represents something other than attitude towards risk (assuming our index of risk aversion is valid). Alesina and La Ferrara (2001) suggest that the self-employed may benefit less from redistributive policies, or that perhaps they are by nature individualistic and value self-help.

\subsection{Unemployment}

Is unemployment an important determinant of preferences over redistribution, after controlling for income? Table 6 reports the estimated effect of a dummy variable UnemplPast, which is unity when the respondent has experienced unemployment in the past five years. The estimated coefficient is positive, and is both statistically and economically significant.

For expected unemployment, we created a binary variable UnemplFuture, which equals unity if the respondent answered affirmatively to the question: "Do you think either you or anyone in your family is going to be unemployed within two years?" The coefficient of this variable also turned out to be positive and significant at the $1 \%$ significant level.

Thus, for both variables, the marginal effect is estimated to be about $8 \%$. That is, if the respondent experienced unemployment in the recent past, or is expecting to do so in the near future, the predicted probability that he or she supports more redistribution is about $8 \%$ higher than otherwise. This is quantitatively important. It largely offsets the marginal effect of moving from the lowest income group to the highest (which is $-10 \%$ ). Taken at face value, this implies that to keep unchanged some newly unemployed person's opinion about redistribution, he/she must be compensated for his/her household income by an amount of that order (for instance, the difference between the average incomes of the lowest income group and the highest is roughly equal to $\$ 100,000)$. UnemplPast and UnemplFuture are different variables. UnemplFuture takes its highest value (about 50\%) for the 50s age group, although the average value of UnemplFuture is $38 \%$ for the whole sample. On the other hand, UnemplPast does not change very much by age group. The coefficient of correlation between UnemplPast and UnemplFuture is 0.212 . 
We have seen that even after controlling for current income and wealth, unemployment exerts a sizeable influence on preferences concerning redistribution. An implication is that the measurement of welfare loss using only current income or consumption may be biased downwards. Empirical results that are consistent with this point have already been obtained by researchers on subjective measures of well-being, such as happiness or life satisfaction (Frey and Stutzer, 2002b, Ohtake and Tomioka, 2004).

One can think of two explanations for unemployment's being an important factor independently of income. First, unemployment may be accompanied by only a small reduction in current income but a large reduction in lifetime income. This could occur for someone who recently experienced unemployment if the wage profile of the former job was much steeper than that of the current job, with the change in the current wage level being rather small. Secondly, unemployment can involve not only a monetary loss but also serious psychological shocks, such as the loss of self-confidence and the loss of attachment to a workplace. Later, we examine these two possibilities by controlling for changes in consumption and income.

\subsection{Unemployment for young and old}

The cost of losing a job may not be the same across age groups. In particular, since the elderly are more likely to retire, they probably do not consider the effect of unemployment (be it monetary or psychological) as seriously as do younger persons. We now examine this by interacting the unemployment variables with age dummies.

The estimation result in Table 7 is roughly consistent with our conjecture. Of the respondents who were recently unemployed, only those in their twenties (for whom UnP_20s is unity) have a strong tendency to approve more redistribution. Its coefficient is statistically significant at the $1 \%$ level, and the estimated marginal effect is $21.3 \%$ (the base group is people of any age with no recent experience of unemployment). Turning next to those who are expecting unemployment, we found that people in their thirties and forties tend to favor greater redistribution of income, with the latter age group having a larger marginal effect (19\%). People in their fifties and sixties show 
no inclination to accept more redistribution, even if they were recently unemployed or expect to be.

We examine this issue further by comparing the results across two income groups, the wealthy and the poor. In the second column of Table 7, we estimated the same model as previously but using only respondents with household income below the 50th percentile in the sample. Table 7 reveals that, among the recently unemployed, income redistribution policy was supported by people in their twenties and (to a lesser extent) by those in their fifties. On the other hand, expected unemployment has no significant effect on any age group, although the marginal effect for those in their forties is rather large and on the borderline of significance at the $10 \%$ level.

The third column of Table 7 reports the estimates for those above the 50th percentile of household income. Despite a quite large positive marginal effect of UnP_20s (32\%), experiences of unemployment are not statistically significant for all age groups. The estimated effects of future unemployment for those in their thirties and forties have economically important magnitudes, and the effect of the latter is also statistically significant.

In sum, regardless of income, it appears that for the elderly, neither expected nor experienced unemployment has any effect on preferences for redistributive policy. Costs of being unemployed differ across age groups. As suggested before, the reason may be that, since elderly people are retiring anyway, neither their lifetime income nor their psychology is affected by unemployment. This is interesting because, as we have seen, aging itself has a strong positive correlation with approval for redistribution.

Meanwhile, estimated effects of pure age dummies on the dependent variable show distinct patterns across income groups. Comparing the estimation results for rich and poor in Table 7, we find that only in the low-income sample are age dummies positively and significantly correlated with the dependent variable, entirely as expected: since the relatively poor elderly have few prospects of upward mobility, it is natural that they support extensive redistribution of income.

Finally, women differ in their attitudes towards redistribution by income group. The third 
column of Table 7 reports that rich women have a rather strong aversion to more income redistribution: among the higher income group, a married (resp. a single) woman is predicted to be $14.7 \%$ (resp. $23.2 \%$ ) less likely than a married man to agree to such a scheme, whereas the second column of Table 7 indicates that among the lower income group, there is little difference between the genders.

We do not know why rich women are more negative about redistributive policies than are rich men. As shown, marital status is estimated to be irrelevant (unlike in the US, according to Edlund and Pande, 2002). As discussed earlier, in other developed countries women are found to be in sympathy for income redistribution and the welfare state in general.

\subsection{Changes in income and consumption}

Earlier, we suggested that unemployment involves more than a monetary loss, and may include psychological shocks. However, it could be that the unemployment variables represent variations in expected future income or consumption (perhaps they obtain new information from the experience and adjust their own economic expectations), and that such variations are not well captured by current income, which is measured in absolute terms. If so, we should not interpret the significance of the unemployment variables (after controlling for current income) as evidence that the unemployed suffer a nonmonetary loss.

To examine this issue, we created the variable ConsChange, which takes five distinct values $(-7,-2.5,0,2.5,7)$. It is based on our survey question about the percentage change in consumption between the previous year and the year before. We also constructed an analogous variable for past income variation, IncChange. The result in Table 8 suggests that a change in consumption is negatively correlated with the dependent variable, whereas a change in income is not.

We also included dummies for expected income changes in the coming five years. FIncStable (resp. FIncUp) equals unity if the respondent says income will be stable (resp. rising), and zero otherwise. The result in Table 8 implies that people who expect a stable or rising income are 
relatively negative about redistribution compared to those who expect a fall in income.

We see that even after controlling for these variables, the coefficient of past unemployment is still large and positive, although that of future unemployment is no longer statistically significant. This result is consistent with the view that there exist not only pecuniary but also psychological costs of unemployment.

\subsection{Mobility}

Even the poor may be hostile to redistribution if they believe strongly that social mobility is sufficiently high. The rich may demand more redistribution today if they expect to fall down the income ladder in the near future. We now examine what our data has to say on this issue.

A binary variable PoorGotRich equals unity if the respondent agreed with the view that "in the past five years the poor have had a greater chance of getting rich." Likewise, RichGotPoor is a dummy variable that indicates whether the respondent thinks "in the past five years the rich have had a greater probability of getting poor".

Table 8 shows that the coefficients of these variables are estimated to be negative and positive, respectively. In this sense, those who feel that upward social mobility has recently increased tend to oppose more redistribution. More downward social mobility leads people to approve greater redistribution. That is, social mobility and income redistribution are perceived to be substitutes. Nevertheless, these two estimates are not statistically significant.

Unlike a change in general social mobility, increased poverty turned out to be quite important. MorePoor is a dummy that indicates whether the respondent feels the incidence of homelessness and/or family poverty has increased in the past five years. It has a marginal effect of $13.4 \%$, and is statistically significant at the $1 \%$ level.

An interpretation of this finding is that people extract signals of mobility more easily and impressively from a change in extreme poverty than from a change in general social mobility. Another explanation, based on externalities, is that a rise in general poverty makes currently well-off people fear social unrest and crimes, thereby inducing them to vote for alleviating 
poverty by redistribution. Although the rich will not be direct beneficiaries of such a policy, they will benefit from it indirectly. On the other hand, greater general downward mobility, as distinct from more poverty, is perhaps not sufficiently strong or impressive for this sort of mechanism to take effect.

Incidentally, in estimates not reported here, we found no significant correlation between the dependent variable and indices of personal mobility (as defined by the difference in (1) one's own educational level and that of one's parents and (2) the subjective evaluation of one's current living standards and those of one's childhood). In addition, we could not reject the null hypothesis that subjective evaluation of current living standards has a zero coefficient, even at the $10 \%$ significance level.

\subsection{The rich and the poor}

Table 8 also reports estimation results for two income groups, namely those below and those above the 50th percentile of household income. That attitudes of women and the effect of aging are different across income groups has already been discussed. The self-employment dummy is significant only in the sample for the rich. The two unemployment variables have opposite effects: only past unemployment is significant among the poor, whereas among the well-off it is future unemployment that is important.

Among the rich, the increase in consumption is negatively correlated with the dependent variable and is quite significant, while it is not so in the lower-income group. One explanation relates to liquidity constraints: perhaps many high-income households do not face a liquidity constraint, and so a recent change in their consumption level could reflect an unexpected change in future income. On the other hand, the relatively poor probably confront a severe liquidity constraint, and thus a change in consumption would reflect to a large extent a previously anticipated current income shock.

Concerning social mobility and redistributive policy, the estimation results for both income groups are generally the same as those for the whole sample. 


\subsection{Economic inequalities}

We have already seen in our descriptive statistics that many respondents think that economic inequalities of one kind or another have increased in the past few years. Are these perceptions directly related to preferences over income redistribution? The first column of Table 9 shows that the recognition of a rise in income inequality has a large and positive coefficient. This may be because inequality simply offends people's sense of equity. For instance, Alesina, Di Tella and MacCulloch (2001) show that the subjective well-being of a leftist person is negatively affected by greater income inequality. Alternatively, it could be that people interpret greater inequality as a rise in income risk, and hence desire more redistribution to prepare for this increased uncertainty. We found other kinds of inequalities to be insignificant. ${ }^{10}$

\subsection{Altruism and reasons for unemployment}

The next issue we examine is the effect of people's perceptions about the causes of the recent rise in unemployment in Japan. If unemployment is perceived to be largely involuntary, then people may think it desirable that the government should engage in more redistribution of income. We created four binary variables to represent four different views concerning the causes of rising unemployment: the unemployment rate has risen because (1) "more people have difficulty handling new technologies" (NotAdapt); (2) "there are not enough jobs" (NoJobs); (3) "people are lazier and less competent than they were before" (LazyInabil); and (4) "welfare benefits became too generous"(BenDepend).

The first two of these essentially characterize unemployment as "involuntary", and so we expect them to have positive coefficients in our model. The last two are clearly less sympathetic to the unemployed. We thus expect the coefficient of each to have a negative sign. We found that none of these dummies were statistically significant, although the signs were as expected (see the

\footnotetext{
${ }^{10}$ The conclusion regarding the effect of various inequalities on perceptions remains the same when we estimate each of these subjective variables, not simultaneously (as in the text), but separately (not shown). In that case, however, such variables as ConsChange and FIncStable, which becomes insignificant in Table 9 (due probably to collinearity with various subjective variables), turn out statistically significant again, as in Table 8.
} 
second column of Table 9).

Next, we examine the effect of altruism. The dummy variable HelpOthers takes unity if the respondent agreed with the idea that "less fortunate people should be helped by society." Not surprisingly, these people proved quite supportive of greater redistribution. Its marginal effect is larger than that of any other variable analyzed. Note that quite a high percentage of respondents (67\%) expressed altruism.

However, the term altruism may not be entirely appropriate for this variable, because it can be an indicator of the self-interest of the rich who fear negative externalities (such as social unrest triggered by a worsening economic situation). In the face of rising inequality or poverty, the wealthy may rationally seek greater redistribution of income to alleviate adverse externalities.

We should generally be careful not to give causal interpretations of results for subjective explanatory variables (as opposed to the cases of such exogenous variables as age, gender, risk aversion and possibly education or income too). A better and safer interpretation would be that these subjective opinions about society largely reflect individual specific fixed effects and help predict our dependent variable. The large coefficient of, say, HelpOthers is not surprising, because for some people, altruism may be largely synonymous with redistribution from rich to poor. Furthermore, the estimated marginal effect of such a variable would probably be reduced if we could obtain a panel dataset and control for personal fixed effects ${ }^{11}$. The same point would apply to other subjective variables, to varying degrees.

\subsection{Norms and realities}

Table 9 also includes the estimated effects of the discrepancy between norms and realities concerning equality of opportunities. FamilyNR equals unity if the respondent agreed that "one's family background should not be an important determinant of success in society, but in reality is". MobilNR is a dummy that indicates whether the respondent thinks "upward social mobility 
should be high, but in reality is not". These two variables had reasonably large estimated marginal effects and positive signs, indicating that the gap between the norms and realities regarding "equal opportunities for all" is important. Of the two, however, only MobilNR is statistically significant.

\section{Conclusion}

Using an original dataset, we investigated the determinants of individual preferences over income redistribution in Japan. Although income level is negatively correlated with support for redistribution, there are other important factors, which relate to dynamics and uncertainty such as income risk. Even after controlling for income, risk-averse individuals, and those who expect to be unemployed in the future, show a strong tendency to support more redistribution. However, it appears that the elderly do not consider the effect of unemployment as seriously as do younger persons, probably because the elderly are going to retire anyway. As for pure effects of aging and mobility, since the relatively poor elderly have few prospects of upward mobility, they have good reasons to, and indeed do, support extensive income redistribution. Redistribution policy targeted at aged people will be supported. Women oppose more redistribution, in contrast to the case in other developed countries. ${ }^{12}$ Unlike changes in general social mobility, increased poverty is estimated to have a quite important influence.

Altruism is also a key factor, but perhaps the term altruism is not entirely appropriate for the corresponding variable, for even if the rich are not the direct beneficiaries of redistribution, supporting such a policy is consistent with their own self-interest if they fear negative externalities such as social unrest. A rise in income inequality has a positive impact on approval of redistribution. The discrepancy between the norms and realities regarding equality of opportunity influences people's preferences for redistributive policies. Although in this paper we have analyzed the characteristics of supporters of a stronger redistribution system, future research is

11 See Bertrand and Mullainathan (2001) for this and related points.

12 More precisely, we have seen that it is women in the upper-half income group who oppose greater redistribution. Interestingly, using the same dataset we found elsewhere that women tend to be more critical of greater income inequality, compared to men (Tomioka and Ohtake, 2004). Thus, it could be that women support the equlization of 
needed to determine the optimal degree of progressivity in income tax.

before-taz income but not that of after-tax income through forced redistribution by tax and social security. 


\section{References}

Alesina, A. R. Di Tella and R. MacCulloch (2001) "Inequality and Happiness: Are Europeans and Americans Different?", NBER Working Paper, No. 8198.

Alesina, A. and La Ferrara, E. (2001) "Preferences for Redistribution in the Land of Opportunities", NBER Working Paper, No. 8267.

Alesina. A., E. Glaeser and Sacerdote, B. (2001) "Why Doesn't the United State Have a European-Style Welfare State?", Brookings Papers on Economic Activity, No.2, pp. $187-254$

Barr, N. (1992) "Economic Theory and the Welfare State: A Survey and Interpretation”, Journal of Economic Literature, Vol. 30, No. 2, pp.741-803.

Benabou, A. and E. Ok (2001) "Social Mobility and the Demand for Redistribution", Quarterly Journal of Economics, Vol. 116, No. 2, pp.447-87.

Bertrand, M. and S. Mullainathan (2001) "Do People Mean What They Say? Implications for Subjective Survey Data”, American Economic Review, Vol. 91, No. 2, pp.67-72.

Boadway, R. and M. Keen (2000) "Redistribution”, in A. Atkinson and F. Bourguignon (eds), Handbook of Income Distribution, vol.1, Amsterdam: Elsevier, pp. 1-58.

Boskin, M. and E. Sheshinski (1978) “Optimal Redistributive Taxation When Individual Welfare Depends upon Relative Income", Quarterly Journal of Economics, Vol. 92, No. 4, pp. $589-601$.

Edlund, L. and R. Pande (2002) "Why Have Women Become Left-Wing? The Political Gender Gap and the Decline in Marriage", Quarterly Journal of Economics, Vol. 117, No.3, pp. 917-961.

Frey, B. S. and A. Stutzer (2002a) Happiness and Economic, Princeton: Princeton University Press.

Frey, B. S. and A. Stutzer (2002b) “What Can Economists Learn from Happiness Research?”, Journal of Economic Literature, Vol. 40, No. 2, pp.402-435. 
Ishikawa, T. (1999) Economics of Income Distribution (Bunpai No Keizaigaku), Tokyo: University of Tokyo Press.

Krueger, A. (2002) "Inequality, Too Much of a Good Thing”, mimeo, Princeton University.

Meltzer, A. and S. Richards (1981) “A Rational Theory of the Size of Government”, Journal of Political Economy, Vol. 89, pp. 914-927.

Ohtake, F. and M. Saito (1999) “On the Income Inequality during the 1980s: Causes and Implications", Quarterly of Social Security Research, Vol. 35, No. 1, pp. 65-76 (in Japanese)

Ohtake, F. and J. Tomioka (2004) "Happiness and Income Inequality in Japan”, mimeo, Osaka University.

Piketty, T. (1995) “Social Mobility and Redistributive Policies", Quarterly Journal of Economics, Vol. 110, No. 3, pp.551-584.

Putterman, L. J. E. Roemer and J. Silvestre (1998) “Does Egalitarianism Have a Future?”, Journal of Economic Literature, Vol. 36, No. 2, pp.861-902.

Ravallion, M. and M. Lokshin (2000) "Who Wants to Redistribute? The Tunnel Effect in 1990s Russia”, Journal of Public Economics, Vol. 76, No.1, pp. 87-104.

Sato, T. (2000) Japan as an Unequal Society (Fubyoudou Shakai Nippon), Tokyo: Chuokoron-Shinsha.

Tachibanaki, T. (1998) Economic Inequality in Japan (Nihon no Keizai Kakusa), Tokyo: Iwanami Shoten

Tomioka, J. and F. Ohtake (2004) “Perceptions of 'Rising Inequality' in Japan”, mimeo, Osaka University.

Wooldridge, J. (2002) Econometric Analysis of Cross Section and Panel Data, Cambridge, Mass: MIT Press. 
Table 1. Household income quartiles and support for redistribution (\%)

\begin{tabular}{l|ccc|c}
\hline \multicolumn{3}{|c|}{ More Redistribution } \\
Income quartiles & Oppose & Neutral & Support & Total \\
\hline 1 & 11.25 & 30.63 & 58.12 & 100 \\
2 & 13.6 & 29.39 & 57.02 & 100 \\
3 & 20.11 & 31.22 & 48.68 & 100 \\
4 (Top) & 22.81 & 35.31 & 41.88 & 100 \\
\hline Total & 15.87 & 31.67 & 52.46 & 100 \\
\hline
\end{tabular}

Table 2. Age groups and support for redistribution (\%)

More Redistribution

\begin{tabular}{l|ccc|c} 
Age group & Oppose & Neutral & Support & Total \\
\hline $20 \mathrm{~s}$ & 20.65 & 35.87 & 43.48 & 100 \\
$30 \mathrm{~s}$ & 14.59 & 32.62 & 52.79 & 100 \\
$40 \mathrm{~s}$ & 19.44 & 35.42 & 45.14 & 100 \\
$50 \mathrm{~s}$ & 13.59 & 29.08 & 57.34 & 100 \\
$60 \mathrm{~s}$ & 10.86 & 24.57 & 64.57 & 100 \\
\hline Total & 15.87 & 31.67 & 52.46 & 100 \\
\hline
\end{tabular}


Table 3. Gender and support for redistribution (\%)

$$
\text { More Redistribution }
$$

\begin{tabular}{l|ccc|c} 
Gender & Oppose & Neutral & Support & Total \\
\hline Female & 15.69 & 36.03 & 48.28 & 100 \\
Male & 16.02 & 28.04 & 55.94 & 100 \\
\hline Total & 15.87 & 31.67 & 52.46 & 100 \\
\hline
\end{tabular}

Table 4. Employment status and support for redistribution (\%)

More Redistribution

\begin{tabular}{l|ccc|c} 
& Oppose & Neutral & Support & Total \\
\hline Not Unemployed & 16.13 & 32.1 & 51.77 & 100 \\
Unemployed & 6.06 & 15.15 & 78.79 & 100 \\
\hline Total & 15.87 & 31.67 & 52.46 & 100 \\
\hline
\end{tabular}


Table 5. Descriptive statistics of all variables

\begin{tabular}{|c|c|c|c|c|c|c|c|}
\hline Variable & Obs & Mean & Std. Dev. & Variable & Obs & Mean & Std. Dev. \\
\hline Redistr & 1050 & 0.520 & 0.500 & IncChange & 1050 & -0.86 & 3.621 \\
\hline MaleNoMarried & 1050 & 0.135 & 0.342 & ConsChange & 1050 & 0.67 & 3.805 \\
\hline FemMarried & 1050 & 0.28 & 0.449 & FIncStable & 1050 & 0.293 & 0.456 \\
\hline FemNoMarried & 1050 & 0.113 & 0.317 & FIncUp & 1050 & 0.197 & 0.398 \\
\hline age30s & 1050 & 0.186 & 0.389 & PoorGotRich & 1046 & 0.102 & 0.302 \\
\hline age 40s & 1050 & 0.235 & 0.424 & RichGotPoor & 1044 & 0.562 & 0.496 \\
\hline age $50 \mathrm{~s}$ & 1050 & 0.291 & 0.454 & MorePoor & 1047 & 0.852 & 0.355 \\
\hline age60s & 1050 & 0.137 & 0.344 & IncomIneq & 1042 & 0.663 & 0.473 \\
\hline College & 1050 & 0.318 & 0.466 & WealthIneq & 1037 & 0.539 & 0.499 \\
\hline GradSchool & 1050 & 0.025 & 0.156 & IneqSchool & 1041 & 0.23 & 0.421 \\
\hline Estate & 1050 & 2.39 & 2.998 & IneqPart & 1024 & 0.502 & 0.5 \\
\hline FAsset & 1050 & 10.28 & 11.60 & IneqFamily & 1031 & 0.206 & 0.404 \\
\hline HIncClass2 & 1050 & 0.326 & 0.469 & IncomIneqFut & 1044 & 0.753 & 0.432 \\
\hline HIncClass3 & 1050 & 0.267 & 0.442 & WealthIneqFut & 1039 & 0.621 & 0.485 \\
\hline RiskAvs & 1050 & 0.491 & 0.201 & IneqSchoolFut & 1043 & 0.268 & 0.443 \\
\hline SelfEmployed & 1050 & 0.082 & 0.275 & IneqPartFut & 1041 & 0.485 & 0.5 \\
\hline UnemplPast & 1050 & 0.153 & 0.361 & IneqFamilyFut & 1034 & 0.203 & 0.402 \\
\hline UnemplFut & 1050 & 0.382 & 0.486 & NotAdapt & 1040 & 0.546 & 0.498 \\
\hline UnP_age20 & 1050 & 0.035 & 0.183 & LazyInabil & 1045 & 0.5 & 0.5 \\
\hline UnP_age30 & 1050 & 0.035 & 0.183 & NoJobs & 1049 & 0.867 & 0.34 \\
\hline UnP_age40 & 1050 & 0.026 & 0.159 & BenDepend & 1043 & 0.288 & 0.453 \\
\hline UnP_age50 & 1050 & 0.034 & 0.18 & HelpOthers & 1047 & 0.679 & 0.467 \\
\hline UnP_age60 & 1050 & 0.025 & 0.156 & FamilyNR & 1045 & 0.247 & 0.431 \\
\hline
\end{tabular}




\begin{tabular}{llll|llll} 
UnF_age20 & 1050 & 0.065 & 0.247 & MobilNR & 1046 & 0.489 & 0.5 \\
UnF_age30 & 1050 & 0.073 & 0.26 & & & \\
UnF_age40 & 1050 & 0.064 & 0.245 & & & \\
UnF_age50 & 1050 & 0.131 & 0.338 & & & \\
UnF_age60 & 1050 & 0.048 & 0.214 & & & & \\
\hline
\end{tabular}


Table 6. Estimation results for basic model

\begin{tabular}{|c|c|c|}
\hline & Marginal Effect & Std. Err \\
\hline MaleNoMarried & 0.647 & 0.058 \\
\hline FemMarried & $-0.063 *$ & 0.038 \\
\hline FemNoMarried & -0.022 & 0.059 \\
\hline age30s & $0.114^{* *}$ & 0.053 \\
\hline age $40 \mathrm{~s}$ & 0.065 & 0.057 \\
\hline age $50 \mathrm{~s}$ & $0.207^{* * *}$ & 0.060 \\
\hline age60s & $0.272^{* * *}$ & 0.057 \\
\hline College & 0.020 & 0.035 \\
\hline GradSchool & -0.119 & 0.104 \\
\hline Estate & -0.003 & 0.006 \\
\hline FAsset & $-0.004^{* *}$ & 0.002 \\
\hline HIncClass2 & -0.019 & 0.037 \\
\hline HIncClass3 & $-0.105^{* *}$ & 0.047 \\
\hline RiskAvs & $0.200^{* *}$ & 0.079 \\
\hline SelfEmployed & -0.079 & 0.057 \\
\hline UnemplPast & $0.081^{*}$ & 0.045 \\
\hline UnemplFuture & $0.083^{* * *}$ & 0.032 \\
\hline Number of obs & 1122 & \\
\hline Pseudo R2 & 0.0515 & \\
\hline Loglikelihood & -7360.682 & \\
\hline
\end{tabular}

Note: $* * *$ indicates significance at the $1 \%$ level, $* *$ indicates significance at the $5 \%$ level, and * indicates significance at the $10 \%$ level. 
Table 7. Estimation results for models with interaction of unemployment experience and age

\begin{tabular}{|c|c|c|c|c|c|c|}
\hline & \begin{tabular}{|c|} 
All \\
Marginal Effect
\end{tabular} & Std. Err & $\begin{array}{c}\text { Poor } \\
\text { Marginal Effect }\end{array}$ & Std. Err & $\begin{array}{c}\text { Rich } \\
\text { Marginal Effect }\end{array}$ & Std. Err \\
\hline MaleNoMarried & 0.068 & 0.059 & 0.090 & 0.066 & -0.059 & 0.116 \\
\hline FemMarried & -0.066 * & 0.039 & 0.011 & 0.052 & $-0.147_{* * *}$ & 0.054 \\
\hline FemNoMarried & -0.021 & 0.060 & 0.055 & 0.066 & $-0.232_{*}$ & 0.112 \\
\hline age $30 \mathrm{~s}$ & 0.111 & 0.066 & 0.108 & 0.080 & 0.075 & 0.154 \\
\hline age $40 \mathrm{~s}$ & 0.046 & 0.073 & 0.139 & 0.091 & -0.138 & 0.132 \\
\hline age $50 \mathrm{~s}$ & $0.224^{* * *}$ & 0.071 & $0.217^{* *}$ & 0.085 & 0.113 & 0.139 \\
\hline age60s & $0.310^{* * *}$ & 0.065 & $0.317^{* * *}$ & 0.072 & 0.186 & 0.162 \\
\hline College & 0.024 & 0.035 & 0.022 & 0.047 & 0.055 & 0.055 \\
\hline GradSchool & -0.101 & 0.104 & -0.047 & 0.146 & -0.143 & 0.140 \\
\hline Estate & -0.003 & 0.006 & -0.004 & 0.010 & 0.0026 & 0.007 \\
\hline FAsset & $-0.004^{* *}$ & 0.002 & $-0.004^{*}$ & 0.002 & -0.0027 & 0.002 \\
\hline HIncClass2 & -0.014 & 0.037 & & & & \\
\hline HIncClass3 & $-0.095^{* *}$ & 0.047 & & & & \\
\hline Household Inc & & & 0.001 & 0.013 & $-0.022^{* *}$ & 0.01 \\
\hline RiskAvs & $0.203^{* * *}$ & 0.079 & $0.176^{*}$ & 0.104 & $0.201^{*}$ & 0.120 \\
\hline SelfEmployed & -0.078 & 0.057 & -0.028 & 0.075 & $-0.189^{* *}$ & 0.0860 \\
\hline UnP_age20s & $0.213^{* *}$ & 0.079 & $0.216^{* *}$ & 0.079 & 0.323 & 0.181 \\
\hline UnP_age30s & 0.044 & 0.091 & 0.100 & 0.104 & -0.112 & 0.159 \\
\hline UnP_age40s & -0.012 & 0.096 & 0.042 & 0.135 & -0.072 & 0.123 \\
\hline UnP_age 50s & 0.091 & 0.084 & $0.177^{*}$ & 0.092 & -0.09 & 0.150 \\
\hline UnP_age60s & 0.063 & 0.121 & 0.126 & 0.127 & -0.020 & 0.294 \\
\hline
\end{tabular}




\begin{tabular}{l|rr|rr|rr|} 
UnF_age20s & 0.013 & 0.085 & -0.038 & 0.102 & 0.125 & 0.142 \\
UnF_age30s & $0.119^{*}$ & 0.061 & 0.086 & 0.067 & 0.216 & 0.139 \\
UnF_age40s & $0.195^{* * *}$ & 0.064 & 0.146 & 0.084 & $0.249^{* *}$ & 0.102 \\
UnF_age50s & 0.049 & 0.055 & 0.073 & 0.080 & 0.041 & 0.080 \\
UnF_age60s & -0.021 & 0.086 & -0.120 & 0.109 & 0.142 & 0.159 \\
\hline Number of obs & 1122 & & 661 & & 461 & \\
Pseudo R2 & 0.0564 & & 0.0459 & & 0.0946 & \\
Loglikelihood & -732.895 & & -431.158 & & -287.48951 & \\
\hline
\end{tabular}

Note: $* * *$ indicates significance at the $1 \%$ level, $* *$ indicates significance at the $5 \%$ level, and * indicates significance at the $10 \%$ level. 
Table 8. Estimation results for models with perspective on mobility

\begin{tabular}{|c|c|c|c|c|c|c|}
\hline & $\mid \begin{array}{c}\text { All } \\
\text { Marginal Effect }\end{array}$ & Std. Err & Poor & Std. Err & \begin{tabular}{|} 
Rich \\
Marginal Effect
\end{tabular} & Std. Err \\
\hline MaleNoMarried & 0.071 & 0.061 & 0.101 & 0.069 & -0.052 & 0.118 \\
\hline FemMarried & $-0.084^{* *}$ & 0.040 & -0.001 & 0.054 & $-0.191^{* * *}$ & 0.058 \\
\hline FemNoMrried & -0.067 & 0.061 & 0.063 & 0.070 & $-0.242^{*}$ & 0.113 \\
\hline age30s & $0.142^{* *}$ & 0.055 & $0.152^{* *}$ & 0.061 & 0.092 & 0.131 \\
\hline age $40 \mathrm{~s}$ & 0.071 & 0.060 & $0.177^{* *}$ & 0.070 & -0.139 & 0.126 \\
\hline age $50 \mathrm{~s}$ & $0.216^{* * *}$ & 0.065 & $0.269^{* * *}$ & 0.066 & 0.038 & 0.129 \\
\hline age60s & $0.295^{* * *}$ & 0.059 & $0.310^{* * *}$ & 0.067 & 0.165 & 0.144 \\
\hline College & 0.034 & 0.037 & 0.032 & 0.050 & 0.052 & 0.061 \\
\hline GradSchool & -0.148 & 0.111 & -0.077 & 0.163 & -0.173 & 0.148 \\
\hline Estate & -0.004 & 0.006 & -0.011 & 0.010 & 0.005 & 0.008 \\
\hline FAsset & $-0.003^{*}$ & 0.002 & -0.003 & 0.003 & -0.002 & 0.002 \\
\hline HIncClass2 & -0.013 & 0.039 & & & & \\
\hline HIncClass3 & $-0.089^{*}$ & 0.049 & & & & \\
\hline Houseinc & & & 0.004 & 0.013 & $-0.021^{* *}$ & 0.010 \\
\hline RiskAvs & $0.141^{*}$ & 0.081 & 0.116 & 0.109 & 0.117 & 0.123 \\
\hline SelfEmployed & $-0.111^{*}$ & 0.059 & -0.069 & 0.076 & $-0.183^{*}$ & 0.087 \\
\hline UnemplPast & $0.096^{*}$ & 0.049 & $0.169^{* * *}$ & 0.057 & -0.039 & 0.083 \\
\hline UnemplFuture & 0.054 & 0.037 & 0.016 & 0.045 & $0.112^{*}$ & 0.058 \\
\hline IncChange & -0.004 & 0.005 & 0.000 & 0.006 & -0.005 & 0.009 \\
\hline ConsChange & $-0.010^{* *}$ & 0.005 & -0.004 & 0.006 & $-0.020^{* * *}$ & 0.007 \\
\hline FincStable & $-0.076^{*}$ & 0.039 & -0.073 & 0.048 & -0.060 & 0.066 \\
\hline FincUp & -0.034 & 0.046 & -0.077 & 0.059 & 0.023 & 0.073 \\
\hline
\end{tabular}




\begin{tabular}{l|rr|rr|rr|} 
PoorGotRich & -0.072 & 0.058 & -0.072 & 0.073 & -0.108 & 0.088 \\
RichGotPoor & 0.025 & 0.034 & 0.034 & 0.043 & 0.027 & 0.054 \\
MorePoor & $0.134^{* * *}$ & 0.044 & $0.142^{* *}$ & 0.061 & $0.150^{* *}$ & 0.067 \\
\hline Number of obs & 1043 & & 607 & 436 & \\
Pseudo R2 & 0.072 & & 0.059 & & 0.1197 & \\
Loglikelihood & -670.496 & & -390.550 & & -264.239 & \\
\hline
\end{tabular}

Note: $* * *$ indicates significance at the $1 \%$ level, $* *$ indicates significance at the $5 \%$ level, and $*$ indicates significance at the $10 \%$ level. 
Table 9. Estimation results for the models with inequality and unemployment perspectives

\begin{tabular}{|c|c|c|c|c|}
\hline \multirow[b]{3}{*}{ IncChange } & \multicolumn{2}{|l|}{ (1) } & \multicolumn{2}{|l|}{ (2) } \\
\hline & Marginal Effect & Std. Err & Marginal Effect & Std. Err \\
\hline & -0.007 & 0.005 & -0.001 & 0.005 \\
\hline ConsChange & -0.007 & 0.005 & -0.008 & 0.005 \\
\hline FincStable & -0.064 & 0.041 & -0.053 & 0.041 \\
\hline FincUp & -0.031 & 0.047 & 0.011 & 0.046 \\
\hline IncomIneq & $0.101^{* *}$ & 0.049 & & \\
\hline WealthIneq & -0.004 & 0.046 & & \\
\hline IneqSchool & -0.022 & 0.051 & & \\
\hline IneqPart & 0.006 & 0.043 & & \\
\hline IneqFamily & 0.067 & 0.05 & & \\
\hline IncomIneqFut & -0.042 & 0.056 & & \\
\hline WealthIneqFut & -0.038 & 0.047 & & \\
\hline IneqSchoolFut & -0.025 & 0.047 & & \\
\hline IneqPartFu & 0.030 & 0.044 & & \\
\hline IneqFamilyFut & 0.035 & 0.05 & & \\
\hline NotAdapt & & & 0.007 & 0.032 \\
\hline LazyInabil & & & -0.011 & 0.036 \\
\hline NoJobs & & & 0.071 & 0.051 \\
\hline BenDepend & & & -0.023 & 0.040 \\
\hline HelpOthers & & & $0.292 * * *$ & 0.038 \\
\hline FamilyNR & & & 0.059 & 0.040 \\
\hline MobilNR & & & $0.071^{* *}$ & 0.034 \\
\hline Number of obs & 902 & & 1030 & \\
\hline
\end{tabular}




\begin{tabular}{l|r|r} 
Pseudo R2 & 0.0698 & 0.127 \\
Loglikelihood & -581.303 & -622.455 \\
\hline
\end{tabular}

Note: In addition to those shown in the Table, the estimated models include regressors used in the model of Table 6, (namely, MaleNoMarried, FemMarried, FemNoMarried, age30s, age40s, age50s, age60s, College, GradSchool, Estate, FAsset, HIncClass2, HIncClass3, RiskAvs, SelfEmployed, UnemplPast, UnemplFuture). *** indicates significance at the $1 \%$ level, $* *$ indicates significance at the $5 \%$ level, and * indicates significance at the $10 \%$ level. 


\section{Appendix: Variable definitions}

Redistr: dummy equal to 1 if respondent thinks that the government should engage in more redistribution of income from rich to poor. The original survey question is: "If the government was going to implement the following policies, would you support or oppose them? 1. Increasing redistribution of income from rich to poor using tax and social security system.” Answers were selected from a scale of 1 to 5, where 1=Support; $2=$ Some support; 3 = Undecided; 4 = Rather opposed; 5 = Oppose. Our dependent variable equals unity if the respondent chooses 1 or 2.

age20s: dummy equal to 1 if respondent is in his or her 20s. Similarly for 30s, 40s, 50s and 60s.

MaleNoMarried: dummy equal to 1 if respondent is a male and not married.

FemMarried: dummy equal to 1 if respondent is a female and married.

FemNoMarried: dummy equal to 1 if respondent is a female and not married.

DivSep: dummy equal to 1 if respondent is either divorced or separated.

College: dummy equal to 1 if respondent is a college graduate.

GradSchool: dummy equal to 1 if respondent has a degree from a graduate school.

Estate: real estate owned by the household, in millions of Yen.

FAsset: financial assets of the household, in millions of Yen.

HIncClassN: Nth household-income class, where $\mathrm{N}$ is either 1, 2 or 3 where 3 is the highest.

HousInc: household income, in millions of Yen.

RiskAvs: this variable is based on the answer to the following survey question: "What is the lowest percentage of rainfall forecast that usually makes you take an umbrella with you when going out?" and is specifically constructed as 1 - (the suggested percentage)/100.

SelfEmployed: dummy equal to 1 if respondent is self-employed.

ConsChange: rate of change in the respondent's consumption last year relative to the year before. IncChange: rate of change in the respondent's income last year relative to the year before. FIncUp: dummy equal to 1 if respondent expects household income to be rising during the 
coming five years.

FIncStable: dummy equal to 1 if respondent expects household income to be stable during the coming five years.

UnemplPast: dummy equal to 1 if respondent was unemployed in the past five years.

UnemplFuture: dummy equal to 1 if respondent is expecting to be unemployed within two years.

UnP_age30s: interaction of UnemplPast and age30s ; thus it equals unity if respondent is in his/her 30s and became unemployed in the past five years; similarly for other age groups.

UnF_age30s: interaction of UnemplFuture and age30s; similarly for other age groups.

Unemployed: dummy equal to 1 if respondent is currently unemployed.

Rich: dummy equal to 1 if respondent's household income is equal to or above $50^{\text {th }}$ percentile.

PoorGotRich: dummy equal to 1 if respondent thinks upward mobility has increased in the last five years.

RichGotPoor: dummy equal to 1 if respondent thinks downward mobility has increased in the last five years.

MorePoor: dummy equal to 1 if respondent thinks that the incidence of homelessness and family poverty has increased in the last five years.

IncomIneq: dummy equal to 1 if respondent thinks that income inequality has increased in the last five years.

WealthIneq: dummy equal to 1 if respondent thinks that wealth inequality has increased in the last five years

IneqSchool: dummy equal to 1 if respondent thinks that inequality across different educational backgrounds has increased in the last five years.

IneqPart: dummy equal to 1 if respondent thinks that income inequality between full-time workers and part-time workers has increased in the last five years.

IneqFamily: dummy equal to 1 if respondent thinks that inequality across different family 
backgrounds has increased in the last five years.

IncomeIneqFut: dummy equal to 1 if respondent thinks that income inequality will increase within five years.

WealthIneqFut: dummy equal to 1 if respondent thinks that wealth inequality will increase within five years.

IneqSchoolFut: dummy equal to 1 if respondent thinks that inequality across different educational backgrounds will increase within five years.

IneqPartFut: dummy equal to 1 if respondent thinks that income inequality between full-time workers and part-time workers will increase within five years.

IneqFamilyFut: dummy equal to 1 if respondent thinks that inequality across different family backgrounds will increase within five years.

NotAdapt: dummy equal to 1 if respondent thinks that the unemployment rate rose because some people could not keep up with or handle new technology.

LazyInabil: dummy equal to 1 if respondent thinks that the unemployment rate rose because people have become lazier and less competent.

NoJobs: dummy equal to 1 if respondent thinks that the unemployment rate rose because there have not been enough jobs.

BenDepend: dummy equal to 1 if respondent thinks that the unemployment rate rose because welfare benefits have been too generous.

HelpOthers: dummy equal to 1 if respondent thinks that less fortunate people should be helped by society.

FamilyNR: dummy equal to 1 if respondent thinks that economic inequality due to different family backgrounds should not be large but it actually is.

MobilNR: dummy equal to 1 if respondent thinks that social mobility should be high but is actually low. 
Figure 1. Income groups and attitude towards strengthening income redistribution

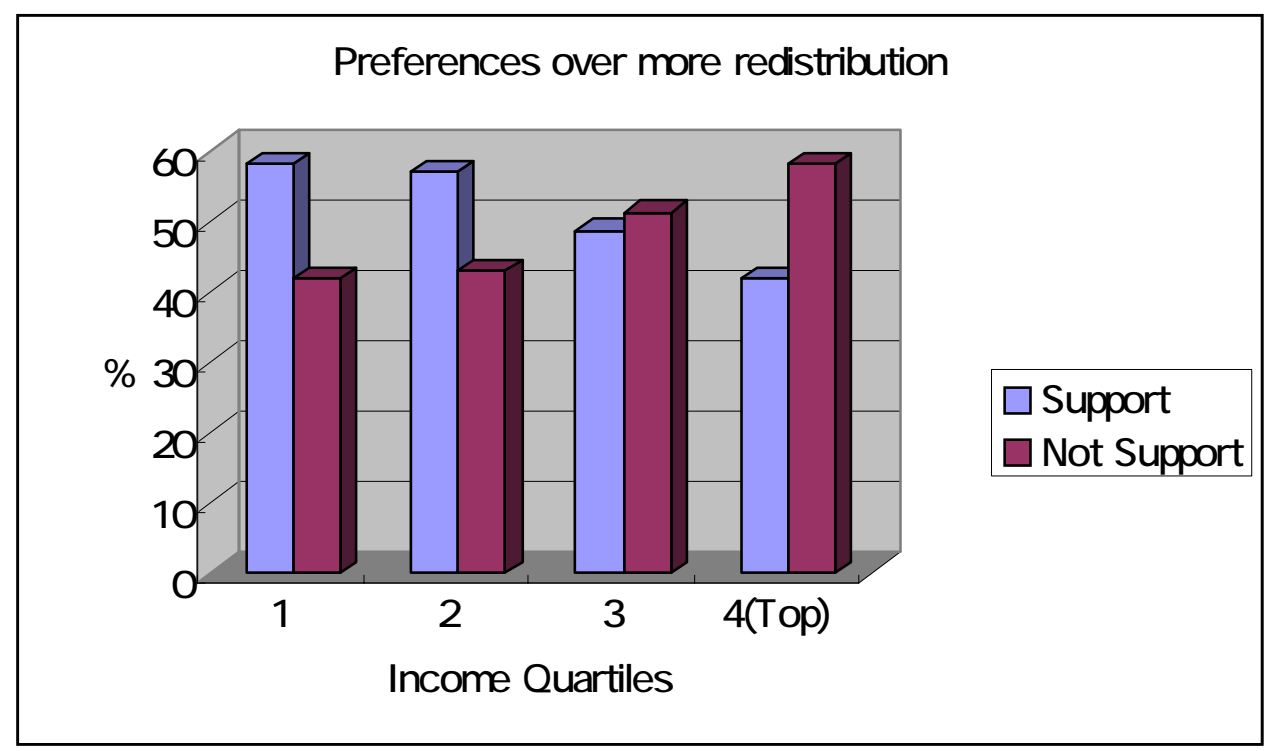

